\title{
Spatial variation in biodiversity, soil degradation and productivity in agricultural landscapes in the highlands of Tigray, northern Ethiopia
}

\author{
Kiros M. Hadgu • Walter A. H. Rossing • \\ Lammert Kooistra • Ariena H. C. van Bruggen
}

Received: 15 October 2008 / Accepted: 17 December 2008 / Published online: 10 February 2009

(C) The Author(s) 2009. This article is published with open access at Springerlink.com

\begin{abstract}
There is a growing concern about food security and sustainability of agricultural production in developing countries. However, there are limited attempts to quantify agro-biodiversity losses and relate these losses to soil degradation and crop productivity, particularly in Tigray, Ethiopia. In this study, spatial variation in agro-biodiversity and soil degradation was assessed in 2000 and 2005 at 151 farms in relation to farm, productivity, wealth, social, developmental and topographic characteristics in Tigray, northern Ethiopia. A significant decrease in agro-biodiversity was documented between 2000 and 2005, mainly associated with inorganic fertilizer use, number of credit sources and proximity to towns and major roads. Agrobiodiversity was higher at farms with higher soil fertility (available $\mathrm{P}$ and total $\mathrm{N}$ ) and higher productivity (total caloric crop yield). Low soil organic matter, few crop selection criteria and steep slopes contributed to soil erosion. Sparsely and intensively cultivated land use types, as determined from satellite images, were associated with high and low agro-biodiversity classes, respectively, as determined during on-farm surveys in 2005. This study
\end{abstract}

\footnotetext{
K. M. Hadgu • W. A. H. Rossing • A. H. C. van Bruggen ( $₫)$ Biological Farming Systems Group, Wageningen University, Marijkeweg 22,

6709 PG Wageningen, the Netherlands

e-mail: ariena.vanbruggen@wur.nl

K. M. Hadgu

e-mail: kirhadgu@gmail.com

W. A. H. Rossing

e-mail: walter.rossing@wur.nl

L. Kooistra

Geo-Information Science and Remote Sensing,

Wageningen University,

P.O. Box 47, 6700 AA Wageningen, the Netherlands

e-mail: lammert.kooistra@wur.nl
}

gives insight into the recent changes in and current status of agro-biodiversity and soil degradation at different spatial scales, which can help to improve food security through the maintenance of agro-biodiversity resources.

Keywords Biodiversity · GIS · Productivity · Soil degradation $\cdot$ Spatial scales

\section{Introduction}

Population growth, environmental change, increasing food demands and globalization of agricultural markets are adversely affecting agro-biodiversity and ecosystem functions (MEA, 2005; Mooney et al. 2005). Agro-biodiversity has been defined as the diversity of habitats, species, crop and animal varieties or races (Wood and Lenné 1999), but also as the genetic variation within different agricultural sectors (Qualset et al. 1995). Agro-biodiversity, as used in this study, refers to crop species and varieties (or land races) and tree and shrub species in agricultural landscapes as affected by socio-economic decisions by individual farmers, local administrators and national policy makers (Jackson et al. 2007). Land use change is exerting the largest impact on agrobiodiversity loss (Chapin III et al. 2000). There is especially concern about the loss of agro-biodiversity as a result of changes in land use affecting the sustainability of agricultural production and food security in the tropics (Thrupp 2000). Here we focus on sustainable use and conservation of agrobiodiversity in agricultural landscapes in Ethiopia.

Agro-biodiversity provides ecosystem services which can contribute to the improvement of agricultural productivity (McNeely and Scherr 2003; MEA 2005). These ecosystem services include: yield improvement by intercropping, i.e. cultivation of two or more crops in alternate 
rows on the same field (Vandermeer et al. 2002), or mixed cropping, i.e. cultivation of two or more crops simultaneously on the same field without arrangement in rows (Zhu et al. 2000), and soil fertility enrichment (e.g. soil nitrogen) by perennial plants in agricultural landscapes (Drinkwater et al. 1998). In addition, agro-biodiversity provides insurance for agricultural production by increasing resilience, i.e. speedy recovery from a disturbance or stress, and decreasing the risk of crop failure (Swift et al. 2004; Tscharntke et al. 2005). However, expansion and intensification of agricultural land threaten agro-biodiversity (Tilman et al. 2001; Tscharntke et al. 2005). The loss of agrobiodiversity is exacerbated by the loss of traditional farming practices in the tropics (Thrupp 2000). These changes are usually accompanied by agricultural land use intensification including removal of trees and shrubs, use of inorganic fertilizer, a shift to a few potentially high yielding crop varieties, and the use of pesticides (MEA 2005; Mooney et al. 2005).

In Ethiopia, where agriculture is based on smallholder farming systems, increased food demand, mainly due to increasing population density, is the main reason for the conversion of natural habitats to agricultural land (Hadgu et al. 2008b). The consequence of expanding land use for agriculture is increased vulnerability of rural landscapes from which poor farmers directly derive ecosystem services (WRI 2005). However, there have been few attempts to explore agro-biodiversity losses and explain these losses from combined topographical, farming systems and farmer socio-economic data. Local decision makers have not paid much attention to agro-biodiversity conservation either, due to a lack of awareness of the magnitude of the problem or the pressure to give more attention to immediate crises of increasing food demand in response to population increase and globalization of agricultural markets.

A recent analysis of spatially explicit land use/land cover changes showed that road networks and settlement expansions were the major drivers for large reductions in natural habitats, mainly at locations with steep slopes in the highlands of Tigray, northern Ethiopia, between 1964 and 2005 (Hadgu et al. 2008b). In the same study period, an increase in agricultural land was observed mainly because of increasing human population. Furthermore, increased access to credit and more inorganic fertilizer use, especially at farms located close to urban areas and major roads was associated with the decrease in agro-biodiversity, which in turn was positively associated with soil erosion in Tigray, in 2000 (Hadgu et al. 2008a). A greater number of soil types per farm, higher farm altitude, larger numbers of planted crop types per farm, greater number of crop selection criteria per farm and more livestock units per farm were associated with increased agro-biodiversity and decreased soil erosion (Hadgu et al. 2008a). Moreover, field measure- ments in part of the same study area in 2005 showed that crop productivity and soil moisture contents were higher at field locations close to tree trunks of Acacia albida Del. (synonym Faidherbia albida (Del.) A. Chew.) compared to locations outside the tree canopy for different $A$. albidabased land use systems (Hadgu et al. 2008c). This indicates that the presence of trees contributes to crop productivity at the prevailing production levels, and challenges policies promoting the sole reliance on external inputs.

In this study, we compared the spatial variation in agrobiodiversity and soil degradation in agricultural landscapes in Tigray in 2000 and 2005. Our operational definition of agro-biodiversity is the sum of the number of tree- or shrub species per farm (tree/shrub diversity) and the number of land races per farm (crop diversity). Soil degradation is estimated as visible soil erosion (Hadgu et al. 2008a). Based on our previous studies in this region (Hadgu et al. 2008a, 2008b, 2008c), we hypothesize that agro-biodiversity and crop productivity have declined in recent years, while soil erosion has increased. To test these hypotheses, on-farm surveys were conducted in 2005 , and the data were, as much as possible, compared with similar data collected in 2000 (Hadgu et al. 2008a). The specific aims of the study were to assess changes in spatial agro-biodiversity and soil degradation in relation to farm characteristics, wealth characteristics, social characteristics, development indicators and topographic characteristics. The ultimate aim of this study was to enhance our understanding of the drivers of agricultural intensification and associated loss of agro-biodiversity, to relate agro-biodiversity to agricultural productivity, and to provide recommendations for local policy makers on approaches to integrate agrobiodiversity conservation and the promotion of sustainable agriculture.

\section{Materials and methods}

\section{Study area}

The study was carried out in the highlands of Tigray in Northern Ethiopia (Fig. 1). The study area $\left(4^{\circ} 82^{\prime}-5^{\circ} 10^{\prime} \mathrm{N}\right.$ and $15^{\circ} 66^{\prime}-15^{\circ} 28^{\prime}$ E) is located South-East of the town of Adwa and covers an area of about 30 by $40 \mathrm{~km}$ at an elevation of 1,300-2,800 $\mathrm{m}$ above sea level (m.a.s.1.). The climate of the area is semi-arid, with two rainy seasons, the main season starting in late June and lasting until September, and a minor season between March and April. The average annual rainfall ranges from $740 \mathrm{~mm}$ at 1,500 m.a.s.l. to $900 \mathrm{~mm}$ at 2,000 m.a.s.l. (Deurloo and Haileselassie, 1994). Wide variation in rainfall from year to year is characteristic for the study area. Soils are categorized as Cambisols, Fluvisols, Xerosols, Vertisols and 


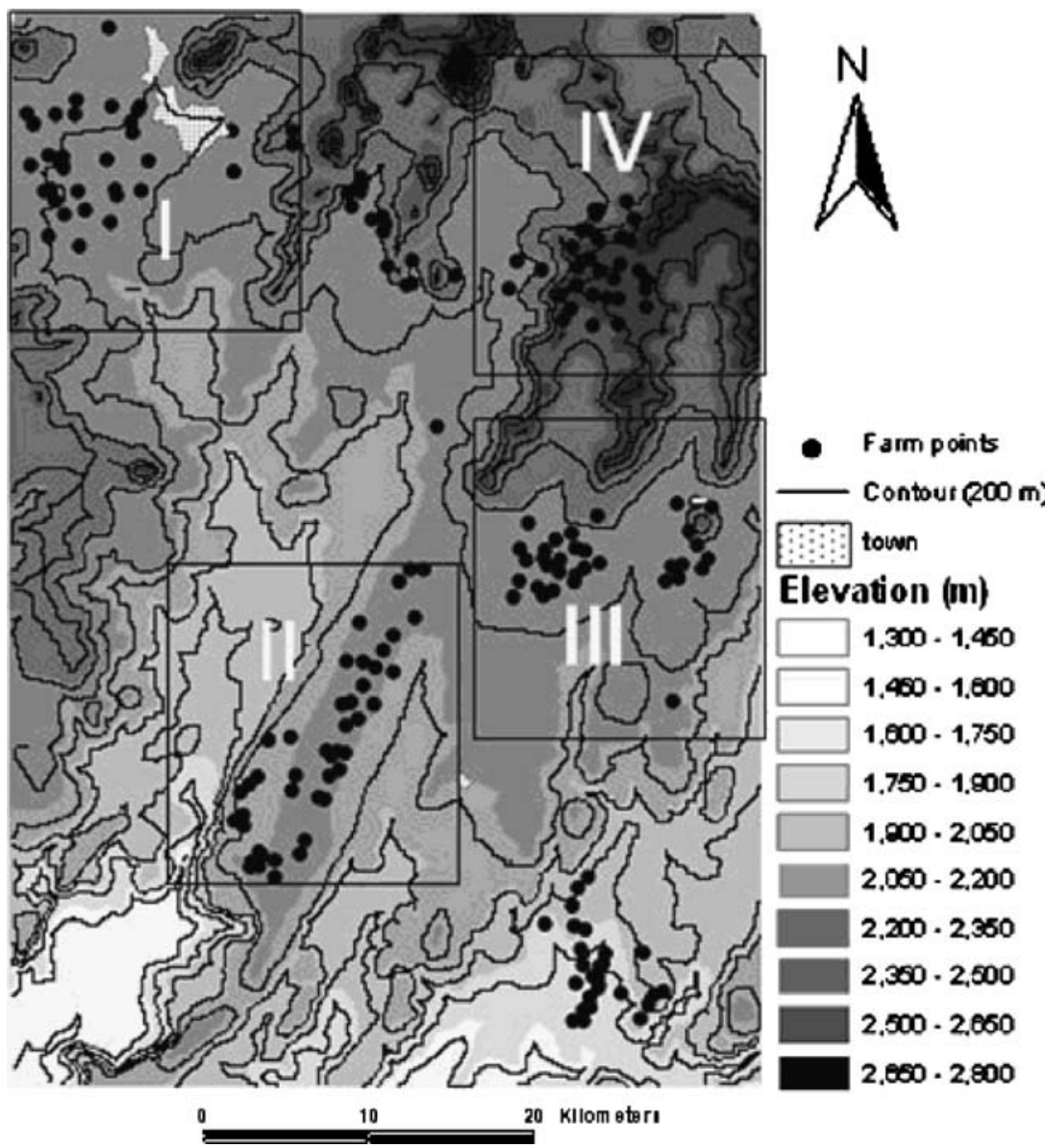

Fig. 1 Elevation map of the study area in Tigray, northern Ethiopia, indicating the location of selected farms in regions I - IV

Luvisols (Sarraute and Vonder 1994). The study area is considered to be one of the most densely populated areas in Ethiopia (Feoli et al. 2002). Land use within the area consists of four dominant classes: woodland, shrub land, scrubland and agricultural land (Hadgu et al. 2008b). The typical agricultural practice in the study area is a mixed crop-livestock small-holder farming system, where farm families of about eight people produce mainly for home consumption. The farm size is generally 1 ha, and different crops are frequently grown in mixtures in the same field. The main crop types in the study area are: tef (Eragrostis tef (Zuccagni) Trotter), barley (Hordeum vulgare L.), wheat
(Triticum spp.), maize (Zea mays L.), sorghum (Sorghum bicolor L.), finger millet (Eleusine coracana (L.) Gaertn.), faba bean (Vicia faba L.) and chickpea (Cicer arietinum L.). Different degrees of agricultural intensification can be distinguished in the study area ranging from sparsely cultivated (Scu) to intensively cultivated (Icu) areas, depending on the extent of removal of the natural vegetation (Table 1) (Hadgu et al. 2008b).

Out of five regions surveyed in 2000 (Hadgu et al. 2008a), four regions (I-IV; Fig. 1) were revisited in 2005, using latitude, longitude and altitude data collected with a hand held Global Positioning System (GPS) (GARMIN

Table 1 Agricultural land use types for the study area in Tigray, northern Ethiopia

\begin{tabular}{ll}
\hline Land use type & Description \\
\hline $\begin{array}{l}\text { Sparsely Cultivated land } \\
(\mathrm{SCu})\end{array}$ & $\begin{array}{c}\text { Between } 20 \text { and } 40 \% \text { of the mapping unit is under cultivation while the remaining area is covered by trees, shrubs, } \\
\text { grasses or herbs. } \\
\text { Moderately cultivated land } \\
(\mathrm{MCu})\end{array}$ \\
$\begin{array}{c}\text { Between } 40 \text { and } 70 \% \text { of the mapping unit is under annual and perennial crop while the remaining area is covered } \\
\text { by trees, shrubs, grasses or herbs. } \\
\text { Intensively Cultivated land } \\
\text { Over } 70 \% \text { of the land is under annual and perennial crops while the remaining area is covered by trees, shrubs, } \\
\text { grasses or herbs. }\end{array}$
\end{tabular}


International Inc., Kansas) in 2000. The area that was left out in 2005 concerned a lowland region with different crops and farm management. Elevation in the four regions ranges from intermediate altitude $(1,600-1,900$ m.a.s.l.) to high altitude (>1,900 m.a.s.1.). Selection of the four regions was based on a land use map derived from remote sensing data (Hadgu et al. 2008b) and an elevation map of the study area created from a Digital Elevation Model (DEM) which in turn was generated from the Shuttle Radar Topographic Mission (SRTM) (USGS, Sioux Falls, SD). This resulted in regions with the following characteristics:

Region I: Area with agriculture only: intensively cultivated (with few or no trees or shrubs) located close to the town of Adwa at 1,900-2,200 m.a.s.l.

Region II: Agriculture-dominated area: intensively (with no or few trees/shrubs) or moderately cultivated (with moderate numbers of trees/ shrubs), located at 1,600-1,900 m.a.s.l. Natural vegetation and agriculture in this region co-exist but the latter is dominant.

Region III: Natural vegetation dominated area, located at 1,900-2,200 m.a.s.1.: both natural vegetation and agriculture (moderately cultivated) are present but natural vegetation is dominant in the area.

Region IV: Natural habitats: almost completely covered by natural vegetation with limited agricultural activities (sparsely cultivated), located above 2,200 m.a.s.l.

Dataset and study approach

Data were collected by a combination of field measurements, farm surveys and GIS analyses in order to explore the changes in spatial variation in agro-biodiversity and soil degradation between 2000 and 2005 in agricultural landscapes in Tigray, northern Ethiopia.

\section{Field measurement and survey datasets}

In the four regions (Fig. 1), 151 farms were visited in 2000 and again in 2005 by locating their exact geographic coordinates using the GOTO function of the hand held GPS. The farms were selected at random from the Tabias (administrative units) included in the selected regions and considered as strata in the analysis. About $5 \%$ of all households were selected by a systematic sampling technique taking every 10th registered farmer from a list of households in each selected Tabia. Farmers were interviewed based on a questionnaire in the local language and their fields were crossed diagonally two or three times to identify trees and shrubs and to record the number of tree/ shrub species in and around agricultural fields (1 ha per farm). In case plants could not be identified on the spot, samples of trees and shrubs were collected and the species were identified according to the flora of Ethiopia and Eritrea (Edwards et al. 2000). Besides, farmers were asked about the number of planted crops, cultivars and landraces in the year of the survey.

Agro-biodiversity was considered to have two components: tree/shrub diversity, which was quantified as the number of different species of trees and shrubs found in and around each field, and crop diversity, which was measured as the number of distinct crop landraces used in the survey year. Each landrace has a limited range of genetic variation, is adapted to local agroclimatic conditions and has been generated, selected, named and maintained by traditional farmers over many generations (Hadgu et al. 2008a).

Farm characteristics included soil quality (a subjective score by the farmer in 2000), and measured organic matter (OM) content (\%), total $\mathrm{N}(\%)$ and available $\mathrm{P}\left(\mathrm{mg} \mathrm{kg}^{-1}\right)$ in 2005), number of crops planted per year (number farm $^{-1}$ ), animal manure use $\left(\mathrm{kg} \mathrm{ha}^{-1}\right)$, weed species encountered in the farm (counted together with farmers) (number farm ${ }^{-1}$ ) and insect pests as stated by the farmers $\left(\right.$ number farm $^{-1}$ ). In addition, farmers were asked which of the following criteria they used to select land races or cultivars (crop selection criteria-number farm ${ }^{-1}$ ): yield, insect resistance, weed resistance, market value, early maturity, drought resistance, thresh-ability, beverage quality and straw quality.

Caloric yield was not measured in 2000. In 2005, it was estimated as the yield of all crops harvested per farm multiplied by their caloric content (Mcal farm ${ }^{-1}$ ). Yields of the various crops per unit area were not available, as many crops were planted as mixtures. Yield of each crop type per farm was estimated by counting the number of standard sacks $(100 \mathrm{~kg})$ with harvested product per farm. Total grain weights were estimated from the total volume (number of sacks per farm) and were multiplied by the default caloric content of each crop (Borlaug 1996; FAO 2003). The caloric values for all crops were added and expressed as megacalories per farm (Mcal farm ${ }^{-1}$ ). The caloric content of the major crop types in the study area were: tef $1.11 \mathrm{kcal} \mathrm{g}^{-1}$ of unmilled grain, barley $3.90 \mathrm{kcal} \mathrm{g}^{-1}$, wheat $3.85 \mathrm{kcal} \mathrm{g}^{-1}$, maize $3.97 \mathrm{kcal} \mathrm{g}^{-1}$, sorghum $3.97 \mathrm{kcal} \mathrm{g}^{-1}$, finger millet $3.94 \mathrm{kcal} \mathrm{g}^{-1}$, faba bean $4.07 \mathrm{kcal} \mathrm{g}^{-1}$ and chickpea4.07 kcal g${ }^{-1}$ (Borlaug 1996; FAO 2003).

The wealth of each farm household was assessed in both years (2000 and 2005) by inorganic fertilizer use $\left(\mathrm{kg} \mathrm{ha}^{-1}\right)$ and number of credit sources, including Dedebit-a local micro finance institution, local money lenders and/or relatives. Monetary income could not be included, because most farmers produce primarily for home consumption. The 
number of credit sources (number farm ${ }^{-1}$ ) was considered a wealth characteristic because most farmers depend on credit to buy inorganic fertilizer and return their loan in a year. Resource poor farmers usually face difficulty in repaying their credit in the case of crop failure, whereas rich farmers with more credit sources have possibilities of repaying their loans even when there is crop failure. Livestock holding (number of animals farm $^{-1}$ ) was considered as a wealth characteristic because animals provide status in the community and are used as dowry for the bridegroom's family. Employment opportunities were estimated by asking about the number of family members with fulltime or part-time employment outside the farm (number farm ${ }^{-1}$ ) and the level of education of the family (at least primary schoolnumber farm ${ }^{-1}$ ).

Farm distance from the nearest town $(\mathrm{km})$ and major road $(\mathrm{km})$ were considered as development drivers. These distances were determined as described under 2.2.4. Finally, farm elevation $(\mathrm{m})$ and slope (\%) were included as topographic characteristics.

\section{Laboratory analysis}

From the $0-15 \mathrm{~cm}$ plough layer, four soil samples $(1 \mathrm{~kg}$ sample ${ }^{-1}$ ) were collected from the middle of each of four fields ( $0.25 \mathrm{ha})$ at each of the 151 farms ( 1 ha each), pooled per farm and stored in sealed and labeled plastic bags. The collected soil samples were sieved through a $2 \mathrm{~mm}$ mesh, air dried and analyzed according to the methods described in MoNRDEP (1990). Total nitrogen content (\%) was determined using the Kjeldahl method. The Walkley and Black method was used to determine the organic matter content (\%) and available phosphorus was determined by the Olsen method $\left(\mathrm{mg} \mathrm{kg}^{-1}\right)$.

\section{Soil erosion calculation}

In 2000, soil erosion was estimated for the 151 farm fields by visual classification (Hadgu et al. 2008a). In 2005, soil erosion was estimated for the same farm fields by visual classification as well as using the Universal Soil Loss Equation (USLE) (Wischmeier and Smith 1978) which was modified by Hurni (1985) to suit Ethiopian conditions. The visual classification of soil erosion and USLE estimated soil erosion classes were positively correlated $(r=0.92$; $P<0.001)$ in 2005. The USLE equation is an empirical expression which estimates mean annual soil loss in $\mathrm{Mg}$ (i.e. Mega grammes or metric tonnes) per hectare per year based on rainfall amount and intensity, soil erodibility, slope length, slope steepness, crop management and erosion control practice. Based on calculated soil erosion results for 2005 and visual observations for 2000 , soil erosion severity was categorized into four classes: low $\left(<10 \mathrm{Mg} \mathrm{ha}^{-1}\right)$, moderate (10-20 Mg ha $\left.{ }^{-1}\right)$, high $\left(20-30 \mathrm{Mg} \mathrm{ha}^{-1}\right)$ and extremely high $\left(>40 \mathrm{Mg} \mathrm{ha}^{-1}\right)$.

\section{GIS analysis}

An elevation map and buffer maps (area of specified distance around elements on a map) of towns and roads were overlaid with the farm location maps of 2000 and 2005. To produce elevation, slope and contour maps of the study area, the Digital Elevation Model (DEM) from Shuttle Radar Topographic Mission (SRTM) (USGS, Sioux Falls, SD) was used. Spatial data of towns and roads were derived from aerial photographs and topographic maps (Ethiopian Mapping Agency, Addis Ababa) that were converted to digital format as described previously (Hadgu et al. 2008b). Each aerial photograph was geo-referenced with points from 1:50,000 topographic maps and known ground control points (crossing of roads and river junctions) collected from the field with a handheld GPS. Each geo-referenced photograph was orthorectified as described before (Hadgu et al. 2008b). Town and road features were delineated from the ortho-rectified aerial photographs using the on-screen digitization technique. The location of each surveyed farm was recorded with a hand-held GPS. All town, road and farm point features were projected onto the Universal Transverse Mercator (UTM) system, zone 37, Adindan. Distances to the nearest town and major road were calculated by the buffering spatial analysis method in ArcGIS 9.2 (ESRI, Redlands, CA, USA). Proximity of farms to buffered towns and roads was calculated by overlaying the farm point map with the buffered town and road maps. Finally, the farm point map was also overlaid with the elevation map of the study areas.

Land use types for 2005 (Table 1) derived from the Landsat Enhanced Thematic Mapper Plus (ETM+) satellite image were overlaid and intersected with the location map of agro-biodiversity classes using ArcGIS 9.2 (Hadgu et al. 2008b).

\section{Statistical analyses}

The data collected from field measurements, farm surveys and GIS analyses were analysed using SAS (SAS 1999). Analysis of the data of 2000 (including farm and wealth characteristics, topography, development drivers, agro-biodiversity, and soil erosion) has been reported elsewhere (Hadgu et al. 2008a). Here we focus on the data of 2005 (including farm and wealth characteristics, crop productivity, topography, development drivers, social characteristics, agro-biodiversity, and soil erosion) and the comparison between 2000 and 2005 (the common data set). 
After transforming all data to lognormal values, discriminant analyses were carried out to relate various environmental variables to agro-biodiversity and soil erosion. Agro-biodiversity (the sum of tree/shrub species and crop races/varieties) and soil erosion were first categorized into classes. Based on the number of tree/shrub species and landraces (or cultivars) per farm, agro-biodiversity was classified as low $(<7)$, medium $(7-12)$ or high $(>12), 33 \%$ of the data being distributed in each class. Soil erosion severity was grouped into the four classes mentioned above: low $\left(<10 \mathrm{Mg} \mathrm{ha}^{-1}\right)$, moderate $\left(10-20 \mathrm{Mg} \mathrm{ha}^{-1}\right)$, high $\left(20-40 \mathrm{Mg} \mathrm{ha}^{-1}\right)$ and very high $\left(>40 \mathrm{Mg} \mathrm{ha}^{-1}\right)$ soil erosion. Discriminant analysis was then carried out to determine if farms with different agro-biodiversity levels (three classes) could be distinguished on the basis of farm, wealth, productivity, development and topographic characteristics. In addition to these characteristics, tree/shrub diversity and crop diversity were used as explanatory variables in a discriminant analysis of soil erosion (four classes). Potential relationships of agro-biodiversity and soil erosion with social characteristics such as farmer's education and employment opportunities were analysed by chi-square tests, as qualitative data could not be subjected to discriminant analyses.

To determine if the status of farms and farmers had changed over time, paired $t$-tests were carried out to compare farm, wealth and social characteristics between 2000 and 2005. For a spatio-temporal analysis of the changes in agro-biodiversity and soil erosion between 2000 and 2005, the differences in agro-biodiversity and soil erosion between the years were grouped into three classes for each of the spatially-identified farms: decrease, no change and increase between 2000 and 2005. Discriminant analyses were carried out to see whether farm, wealth, development and topographic characteristics contributed to the separation between farms in the different agro-biodiversity change classes.

All log-normal transformed data were first subjected to stepwise discriminant (STEPDISC) analysis to select the classification variables that best discriminated among the different agro-biodiversity and soil erosion classes. Next, canonical discriminant analysis (CANDISC) was used to derive discriminant functions which determined if the distinctions among the classes were statistically significant and which variables contributed significantly to these functions. The thresholds $(T)$ for the selection of variables correlating significantly with discriminant function1 were taken as $T=$ $0.6 / \sqrt{ }$ (eigenvalue) for the analysis with agro-biodiversity as class variable, and $T=0.2 / \sqrt{ }$ (eigenvalue) for the other discriminant analyses (Afifi and Clark 1984). The choice of these thresholds resulted in similar variables selected by the canonical discriminant and the stepwise discriminant analyses.

\section{Results}

Status of agro-biodiversity and soil degradation in 2005

\section{Status of agro-biodiversity}

Agro-biodiversity in relation to qualitative social characteristics Chi-square tests revealed that more off-farm employment opportunities were associated with a higher agro-biodiversity class (low, medium and high) in $2005\left(\chi^{2}=30.81, d f=4\right.$, $P=0.001)$. However, farmer's education was not associated with agro-biodiversity $\left(\chi^{2}=7.59, d f=2, P>0.05\right)$.

Agro-biodiversity in relation to quantitative explanatory variables The three agro-biodiversity classes (low, medium and high) were significantly separated by the explanatory variables (canonical discriminant analysis, Wilks'Lambda value $=0.08 ; P<0.001 ;$ Fig. 2$)$. The first canonical function was significant $(P<0.001)$ and accounted for $97 \%$ of the total variance. The farm characteristics total $\mathrm{N}(\%)$, available $\mathrm{P}\left(\mathrm{mg} \mathrm{kg}^{-1}\right)$, crop types (number farm ${ }^{-1}$ ), animal manure $\left(\mathrm{kg} \mathrm{ha}^{-1}\right)$ and crop selection criteria (number farm $^{-1}$ ) were positively associated with agro-biodiversity in the first canonical function and contributed significantly $(P<0.05)$ to the separation of the three agro-biodiversity classes (Table 2). Farms in the high agro-biodiversity class had $52 \%$ higher available $\mathrm{P}\left(\mathrm{mg} \mathrm{kg}^{-1}\right), 39 \%$ higher total $\mathrm{N}$ (\%), $47 \%$ more crop types (number farm ${ }^{-1}$ ), $71 \%$ higher animal manure use $\left(\mathrm{kg} \mathrm{farm}^{-1}\right), 53 \%$ more animals (number farm $^{-1}$ ) and $42 \%$ more crop selection criteria (number $\mathrm{farm}^{-1}$ ) than farms in the low agro-biodiversity class.

Similarly, caloric crop yield (Mcal farm ${ }^{-1}$ ), animal ownership (number farm $^{-1}$ ), farm distance from the nearest

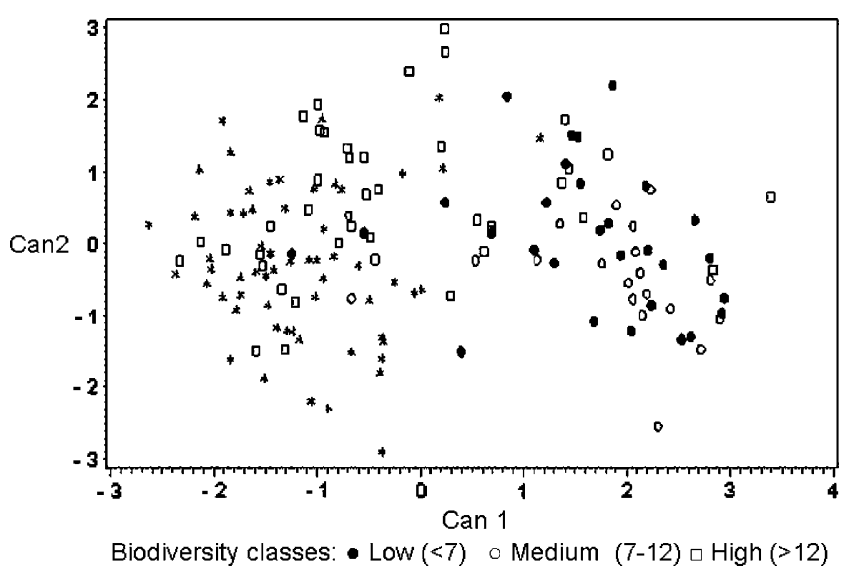

Fig. 2 First and second canonical function from canonical discriminant analysis separating biodiversity classes (number of tree/shrub species and number of crop varieties) in 2005 in Tigray, northern Ethiopia 
Table 2 Variables significantly contributing to the separation between biodiversity classes (low, medium and high) in 2005

\begin{tabular}{|c|c|c|c|c|}
\hline \multirow[t]{2}{*}{ Classification variable } & \multirow{2}{*}{$\begin{array}{l}\text { Pooled within standardized Coefficients } \\
\text { Canonical function } 1\end{array}$} & \multicolumn{3}{|c|}{ Mean values of characteristics per biodiversity class } \\
\hline & & Low $(n=74)$ & Medium (n=27) & High $(n=50)$ \\
\hline Crop types (number.farm $\left.{ }^{-1}\right)^{* a}$ & 0.51 & $3.2( \pm 0.1)$ & $4.2( \pm 0.2)$ & $5.9( \pm 0.1)$ \\
\hline Crop selection criteria (number.farm $\left.{ }^{-1}\right)^{*}$ & 0.36 & $3.9( \pm 0.1)$ & $5.8( \pm 0.2)$ & $6.7( \pm 0.2)$ \\
\hline Caloric crop yield (Mcal.farm $\left.{ }^{-1}\right)^{*} \mathrm{~b}$ & 0.29 & $6106.7( \pm 68.2)$ & $6859.7( \pm 115.9)$ & $7497.1( \pm 139.6)$ \\
\hline Weed species (number.farm ${ }^{-1}$ ) & -0.15 & $4.5( \pm 0.1)$ & $3.6( \pm 0.2)$ & $3.5( \pm 0.2)$ \\
\hline Insect pest species (number.farm ${ }^{-1}$ ) & -0.19 & $2.6( \pm 0.1)$ & $2.2( \pm 0.2)$ & $1.8( \pm 0.1)$ \\
\hline Available soil P $\left(\mathrm{mg} \cdot \mathrm{kg}^{-1}\right)^{*}$ & 0.27 & $12.2( \pm 0.6)$ & $19.7( \pm 1.9)$ & $25.4( \pm 1.2)$ \\
\hline Soil organic matter $(\%)$ & 0.20 & $1.8( \pm 0.1)$ & $2.3( \pm 0.2)$ & $3.4( \pm 0.2)$ \\
\hline Total soil N $(\%)^{*}$ & 0.25 & $0.2( \pm 0.01)$ & $0.2( \pm 0.01)$ & $0.3( \pm 0.01)$ \\
\hline Animal manure $\left(\mathrm{kg} . \mathrm{farm}^{-1}\right)^{*}$ & 0.49 & $266.9( \pm 20.7)$ & $557.4( \pm 39.8)$ & $922.0( \pm 32.8)$ \\
\hline Inorganic fertilizer $\left(\mathrm{kg} \cdot \text { farm }^{-1}\right)^{*}$ & -0.36 & $79.4( \pm 4.0)$ & $50.9( \pm 5.7)$ & $24.7( \pm 4.2)$ \\
\hline Animals (number.farm $\left.{ }^{-1}\right)^{*}$ & 0.38 & $12.7( \pm 0.7)$ & $23.2( \pm 1.2)$ & $27.1( \pm 0.8)$ \\
\hline Credit sources (number.farm ${ }^{-1}$ )* & -0.33 & $2.1( \pm 0.04)$ & $1.9( \pm 0.09)$ & $1.2( \pm 0.06)$ \\
\hline Slope $(\%)$ & -0.04 & $5.2( \pm 0.8)$ & $6.3( \pm 1.4)$ & $3.4( \pm 0.5)$ \\
\hline Elevation $(\mathrm{m})^{*}$ & 0.21 & $1990.7( \pm 4.1)$ & $2069.3( \pm 25.8)$ & $2121.0( \pm 18.1)$ \\
\hline Town distance $(\mathrm{km})^{*}$ & 0.26 & $4.2( \pm 0.3)$ & $7.9( \pm 0.8)$ & $10.2( \pm 0.6)$ \\
\hline Road distance (km) & 0.18 & $2.7( \pm 0.4)$ & $4.8( \pm 0.6)$ & $6.0( \pm 0.4)$ \\
\hline
\end{tabular}

$\mathrm{a} * \mathrm{P}<0.05 ;$ Threshold $=0.6 / \sqrt{ }(8.749)=0.203$

$\mathrm{b}$ The trend in calories yields in different biodiversity classes was similar for all crops except for maize, which had a caloric yield of 814.0, 712.3 and $407.0 \mathrm{Mcal}_{\text {.farm }}^{-1}$ on farms with low, medium and high biodiversity, respectively, partially due to the larger number of maize plants on lowbiodiversity farms. Each farm has 1 ha land

town $(\mathrm{km})$ and elevation $(\mathrm{m})$ contributed significantly $(P<0.05)$ to the discrimination among the agro-biodiversity classes and were positively associated with the first canonical function (Table 2). Compared with farms in the low agrobiodiversity class, those in the high agro-biodiversity class had 19\% higher total caloric crop yield (Mcal farm ${ }^{-1}$ ), especially in farms located at high elevation and far from the nearest town (Table 2).

Wealth characteristics, inorganic fertilizer use $\left(\mathrm{kg} \mathrm{farm}^{-1}\right)$ and credit sources (number farm ${ }^{-1}$ ), were negatively associated with the first canonical function but contributed significantly to the distinction among the three agrobiodiversity classes (Table 2 ). The inorganic fertilizer use $\left(\mathrm{kg} \mathrm{farm}^{-1}\right)$ and access to credit sources (number farm ${ }^{-1}$ ) were 65 and 74\% lower, respectively, for farms in the high compared to the low agro-biodiversity class.

Agro-biodiversity and land use types Farms with low agrobiodiversity were mostly located in areas with intensive and medium cultivated land use (Fig. 3). This was especially true for farms located close to the towns of Adwa and Edaga Arbi. Few farms classified in the low agrobiodiversity class fell in the sparsely cultivated land use class. Sparsely cultivated land use coincided mainly with farms in the high agro-biodiversity class, particularly in region IV, located at high elevation (Fig. 1) and far from the nearest town and major road. Farms in the medium agrobiodiversity class had a mix of land use types (Fig. 3).

\section{Status of soil degradation}

Soil degradation in relation to social characteristics Farms where farmers had more off-farm employment opportunities fell in higher soil erosion classes than farms where farmers had limited employment opportunities $\left(\chi^{2}=20.60\right.$, $d f=8, P<0.05)$. No significance association was revealed between soil erosion classes and farm family education $\left(\chi^{2}=8.44, d f=4, P>0.05\right)$.

Soil degradation in relation to quantitative explanatory variables The explanatory variables (farm and topographic characteristics) significantly distinguished two groups

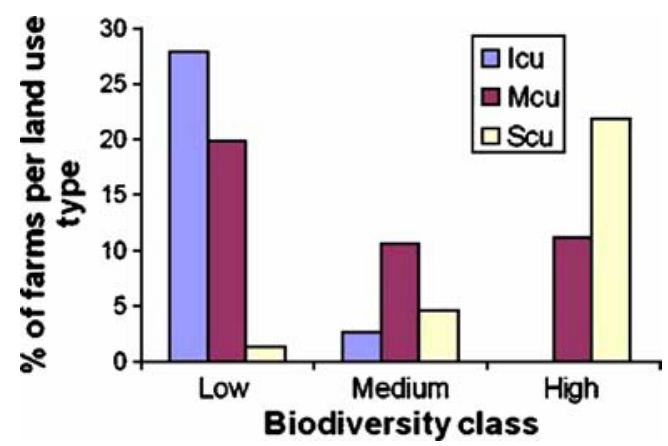

Fig. 3 Relation between biodiversity classes and agricultural land use types for selected farms $(n=151)$ in the Tigray study area in Northern Ethiopia. Land use types: $\mathrm{Scu}=$ Sparsely cultivated; $\mathrm{Mcu}=$ Moderately cultivated; Icu $=$ Intensively cultivated 


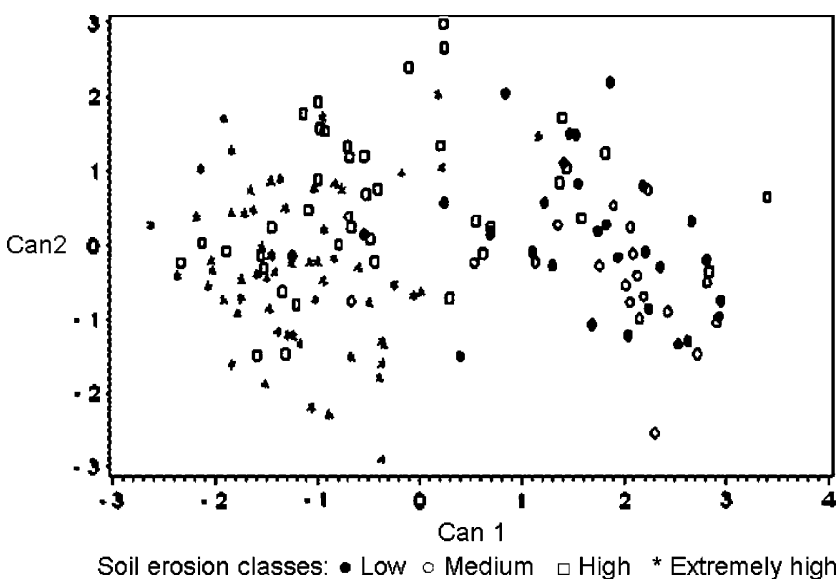

Fig. 4 First and second canonical functions from canonical discriminant analysis separating soil erosion classes in 2005 in Tigray, northern Ethiopia

among the four soil erosion classes, namely low and medium versus high and extremely high soil erosion (canonical discriminant analysis, Wilks' Lambda value $=$ $0.30 ; P<0.001$; Fig. 4). The first canonical function of the discriminant analysis was significant $(P<0.001)$ and explained $84.29 \%$ of the variance. Insect pest species (number farm $^{-1}$ ) and farm slope (\%) were positively associated with the first canonical function and contributed significantly $(P<0.001)$ to the discrimination among the soil erosion groups (Table 3). The higher the slope (\%) of farms, the higher was the soil erosion severity at those farms. Also, the more severe the soil erosion, the larger was the number of insect pest species (number farm $^{-1}$ ), although we do not know the reason for this.
The farm characteristics, soil OM content (\%) and crop selection criteria (number farm ${ }^{-1}$ ) were negatively associated with the first canonical function, which significantly $(P<0.001)$ separated the soil erosion classes (Table 3$)$. This indicated that there was less soil erosion on farms with a higher soil OM content (\%) and number of crop selection criteria (number farm ${ }^{-1}$ ) (Table 3).

Temporal change between 2000 and 2005

\section{Changes in farm and wealth characteristics}

Paired $t$-tests with the data of 2000 and $2005(n=151)$ demonstrated that crop diversity (number farm $\left.{ }^{-1}\right)(t=6.46$, $P<0.001)$, animal ownership (number $\left.\mathrm{farm}^{-1}\right)(t=4.23$, $P<0.001$ ) and crop selection criteria (number farm $^{-1}$ ) $(t=2.05, P<0.05)$ decreased significantly (Table 4$)$. Inorganic fertilizer use $\left(\mathrm{kg} \mathrm{farm}^{-1}\right)$ increased significantly $(t=-3.40, P<0.01)$ between 2000 and 2005 . There was no significant difference $(P>0.05)$ between 2000 and 2005 in the number of tree/shrub species (number farm ${ }^{-1}$ ), soil erosion (category), crop types (number farm ${ }^{-1}$ ), soil types (number farm $^{-1}$ ), credit sources (number farm ${ }^{-1}$ ), weed species (number farm ${ }^{-1}$ ) and insect pest species (number farm ${ }^{-1}$ ).

Agro-biodiversity and soil degradation changes (2000-2005)

Decreases in agro-biodiversity were observed at farms where native species were removed and/or few high-yielding crops were cultivated. Increases in agro-biodiversity occurred only when farms had returned to the use of a variety of

Table 3 Variables significantly contributing to the separation of the soil erosion classes (low, moderate, high and extremely high) in 2005

\begin{tabular}{|c|c|c|c|c|c|}
\hline \multirow[t]{2}{*}{ Classification Variable } & \multirow{2}{*}{$\begin{array}{l}\text { Pooled within standardized Coefficients } \\
\text { Canonical function } 1\end{array}$} & \multicolumn{4}{|c|}{ Mean values of variables per soil erosion class } \\
\hline & & $\begin{array}{l}\text { Low } \\
(n=29)\end{array}$ & $\begin{array}{l}\text { Moderate } \\
(\mathrm{n}=20)\end{array}$ & $\begin{array}{l}\text { High } \\
(n=41)\end{array}$ & $\begin{array}{l}\text { Extremely high } \\
(\mathrm{n}=61)\end{array}$ \\
\hline Tree/shrub species (number.farm ${ }^{-1}$ ) & -0.24 & $11.2( \pm 0.5)$ & $11.1( \pm 0.7)$ & $7.4( \pm 0.6)$ & $5.3( \pm 0.3)$ \\
\hline Crop varieties (number.farm ${ }^{-1}$ ) & -0.25 & $8.7( \pm 0.6)$ & $8.4( \pm 0.6)$ & $5.4( \pm 0.4)$ & $4.0( \pm 0.2)$ \\
\hline Crop selection criteria (number.farm ${ }^{-1}$ )* & -0.27 & $6.5( \pm 0.3)$ & $6.7( \pm .3)$ & $4.9( \pm 0.2)$ & $4.2( \pm 0.1)$ \\
\hline Caloric crop yield (Mcal.farm ${ }^{-1}$ ) & -0.04 & $7282.5( \pm 195.4)$ & $7353.1( \pm 282.3)$ & $6551.9( \pm 116.1)$ & $6312.8( \pm 89.1)$ \\
\hline Weed species (number.farm ${ }^{-1}$ ) & 0.08 & $2.0( \pm 0.2)$ & $3.2( \pm 0.3)$ & $3.9( \pm 0.2)$ & $4.5( \pm 0.1)$ \\
\hline Pest species (number.farm $\left.{ }^{-1}\right)^{*}$ & 0.31 & $2.0( \pm 0.2)$ & $1.4( \pm 0.2)$ & $2.4( \pm 0.1)$ & $2.5( \pm 0.1)$ \\
\hline Available soil P (mg.kg ${ }^{-1}$ ) & -0.15 & $23.8( \pm 1.6)$ & $21.9( \pm 2.0)$ & $18.6( \pm 1.6)$ & $13.3( \pm 0.8)$ \\
\hline Soil organic matter $(\%)^{*}$ & -0.27 & $3.2( \pm 0.3)$ & $3.1( \pm 0.4)$ & $2.2( \pm 0.2)$ & $2.0( \pm 0.1)$ \\
\hline Total soil N (\%) & -0.16 & $0.3( \pm 0.01)$ & $0.3( \pm 0.02)$ & $0.2( \pm 0.01)$ & $0.2( \pm 0.01)$ \\
\hline Animal manure (kg/farm) & -0.20 & $762.1( \pm 59.1)$ & $835.0( \pm 67.9)$ & $562.2( \pm 54.2)$ & $312.3( \pm 29.2)$ \\
\hline Inorganic fertilizer $\left(\mathrm{kg}\right.$. farm $\left.^{-1}\right)$ & 0.03 & $38.3( \pm 6.2)$ & $22.5( \pm 7.7)$ & $54.9( \pm 6.4)$ & $76.6( \pm 4.2)$ \\
\hline Animals (number.farm ${ }^{-1}$ ) & -0.16 & $25.9( \pm 1.5)$ & $25.5( \pm 1.5)$ & $19.6( \pm 1.2)$ & $14.1( \pm 0.9)$ \\
\hline Credit sources (number.farm ${ }^{-1}$ ) & 0.21 & $1.3( \pm 0.09)$ & $1.3( \pm 0.12)$ & $1.7( \pm 0.07)$ & $2.1( \pm 0.06)$ \\
\hline Slope $(\%)^{*}$ & 0.29 & $3.9( \pm 0.7)$ & $2.4( \pm 0.7)$ & $5.1( \pm 0.9)$ & $5.8( \pm 0.9)$ \\
\hline Elevation (m) & -0.21 & $2128.9( \pm 24.8)$ & $2098.4( \pm 29.9)$ & $2038.8( \pm 17.2)$ & $1998.9( \pm 6.8)$ \\
\hline Town distance $(\mathrm{km})$ & -0.01 & $10.8( \pm 0.8)$ & $8.5( \pm 1.0)$ & $6.3( \pm 0.7)$ & $4.8( \pm 0.4)$ \\
\hline Road distance $(\mathrm{km})$ & -0.03 & $6.1( \pm 0.5)$ & $5.4( \pm 0.6)$ & $4.7( \pm 0.5)$ & $2.5( \pm 0.4)$ \\
\hline
\end{tabular}

$* \mathrm{P}<0.05 ;$ Threshold $=0.2 / \sqrt{ }(0.5728)=0.263$ 
Table 4 Mean and standard deviation of all variables assessed in 2000 and 2005 in the Tigray study area in Northern Ethiopia

\begin{tabular}{|c|c|c|c|}
\hline \multirow[t]{2}{*}{ Variable } & \multirow[t]{2}{*}{ Unit } & \multicolumn{2}{|l|}{ Mean \pm SD } \\
\hline & & 2000 & 2005 \\
\hline Tree/shrub species & number.farm ${ }^{-1}$ & $7.9( \pm 3.2)$ & $7.8( \pm 3.7)$ \\
\hline Crop varieties ${ }^{* \mathrm{a}}$ & number.farm ${ }^{-1}$ & $7.0( \pm 3.0)$ & $5.9( \pm 2.9)$ \\
\hline Crop types & number.farm ${ }^{-1}$ & $4.5( \pm 1.4)$ & $4.5( \pm 1.9)$ \\
\hline Crop selection criteria* & number.farm ${ }^{-1}$ & $6.4( \pm 1.7)$ & $5.2( \pm 1.7)$ \\
\hline Caloric crop yield & Mcal.farm ${ }^{-1}$ & $\mathrm{~b}$ & $6701.7( \pm 969.0$ \\
\hline Weed species & number.farm ${ }^{-1}$ & $3.9( \pm 1.2)$ & $4.0( \pm 1.3)$ \\
\hline Pest species & number.farm ${ }^{-1}$ & $2.2( \pm 0.8)$ & $2.2( \pm 0.9)$ \\
\hline Available soil $\mathrm{P}$ & mg.kg ${ }^{-1}$ & $\mathrm{~b}$ & $17.9( \pm 9.5)$ \\
\hline Soil OM & $\%$ & $\mathrm{~b}$ & $2.4( \pm 1.4)$ \\
\hline Total soil $\mathrm{N}$ & $\%$ & $\mathrm{~b}$ & $0.21( \pm 0.1)$ \\
\hline Animal manure & kg.ha ${ }^{-1}$ & $\mathrm{~b}$ & $535.8( \pm 354.8)$ \\
\hline Soil erosion & category. farm ${ }^{-1}$ & $3.6( \pm 1.2)$ & $3.9( \pm 1.2)$ \\
\hline Inorganic fertilizer* & kg.ha ${ }^{-1}$ & $36.8( \pm 46.0)$ & $49.7( \pm 41.1)$ \\
\hline Animals* & number.farm ${ }^{-1}$ & $22.4( \pm 5.3)$ & $19.4( \pm 8.9)$ \\
\hline Credit sources & number.farm $^{-1}$ & $1.8( \pm 0.6)$ & $1.7( \pm 0.6)$ \\
\hline Employment & number.farm ${ }^{-1}$ & $\mathrm{~b}$ & $1.3( \pm 0.5)$ \\
\hline Education & category.farm $^{-1}($ yes $=1 ;$ no $=0)$ & $\mathrm{b}$ & $0.1( \pm 0.3)$ \\
\hline
\end{tabular}

a * Significantly different between 2000 and 2005

b farm characteristic not acquired in 2000

landraces. Agro-biodiversity change (decrease, no change or increase) was separated into distinct groups by the explanatory variables (canonical discriminant analysis, Wilks' Lambda value $=0.61 ; P<0.001$; Fig. 5). Of the total variance, $95.02 \%$ was accounted for by the first canonical function, which was significant $(P<0.001)$. The farm characteristics, crop type (number farm ${ }^{-1}$ ), crop selection criteria (number farm $^{-1}$ ), and animal ownership (number farm $^{-1}$ ), and the development drivers farm distance from the nearest town $(\mathrm{km})$ and road $(\mathrm{km})$ significantly contributed $(P<0.05$; Table 5$)$ to the distinc-

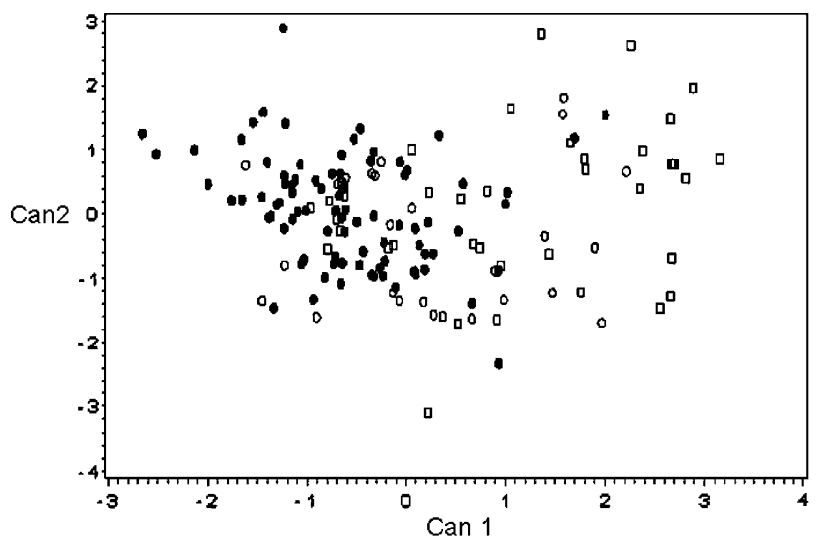

Biodiversity change: $\bullet$ Decreased $(<0) \circ$ No change $(0)$ ㅁnncreased $(>0)$

Fig. 5 First and second canonical function of canonical discriminant analysis separating biodiversity change classes between 2000 and 2005 for the Tigray study area in Northern Ethiopia tion among agro-biodiversity change classes and were positively associated with the first canonical function (Table 5). This implies that where agro-biodiversity increased, this was associated with an increase in crop types (number farm ${ }^{-1}$ ), crop selection criteria (number farm $^{-1}$ ) and animals (number farm ${ }^{-1}$ ). An increase in agro-biodiversity was also observed on farms located far from the nearest town and major road, mainly in region IV (Fig. 1). Inorganic fertilizer use $\left(\mathrm{kg} \mathrm{farm}^{-1}\right)$ also contributed significantly $(P<0.05$; Table 5$)$ to the distinction among classes of agro-biodiversity change between 2000 and 2005 but was negatively associated with the first canonical function (Table 5). More inorganic fertilizer was used $(\mathrm{kg}$ farm $^{-1}$ ) (Table 2 and 4) on farms where agro-biodiversity had decreased between 2000 and 2005.

Classes for changes in soil erosion (decrease, no change and increase) between 2000 and 2005 were not significantly separated by the explanatory variables included (canonical discriminant analysis, Wilks' Lambda value $=0.77 ; P>0.05$; Figure not shown), possibly because different soil erosion estimation methods were used in 2000 (visual assessment) and 2005 (USLE method).

Spatial distribution of agro-biodiversity in 2000 and 2005

Overall tree/shrub diversity did not change significantly between 2000 and 2005 (Table 4), and neither did the spatial distribution of the numbers of tree/shrub species as indicated by the distance analysis of tree/shrub species in buffers around 
Table 5 Variables significantly contributing to the separation among change in biodiversity classes (decrease, no change and increase) between 2000 and 2005

\begin{tabular}{|c|c|c|c|c|}
\hline \multirow[t]{2}{*}{ Classification variable } & \multirow{2}{*}{$\begin{array}{l}\text { Pooled within standardized coefficients } \\
\text { Canonical function } 1\end{array}$} & \multicolumn{3}{|c|}{ Mean values of variables per biodiversity difference class } \\
\hline & & Decrease $(n=84)$ & No change $(n=31)$ & Increase $(n=36)$ \\
\hline Crop type (number.farm $\left.{ }^{-1}\right)^{*}$ & 0.21 & $3.9( \pm 0.2)$ & $4.4( \pm 0.2)$ & $4.9( \pm 0.3)$ \\
\hline Crop selection criteria (number.farm $\left.{ }^{-1}\right)^{*}$ & 0.50 & $4.9( \pm 0.2)$ & $5.3( \pm 0.3)$ & $5.6( \pm 0.3)$ \\
\hline Weed species (number.farm ${ }^{-1}$ ) & -0.11 & $4.2( \pm 0.1)$ & $3.8( \pm 0.2)$ & $3.6( \pm 0.3)$ \\
\hline Pest species (number.farm ${ }^{-1}$ ) & -0.14 & $2.3( \pm 0.1)$ & $2.2( \pm 0.2)$ & $2.1( \pm 0.2)$ \\
\hline Inorganic fertilizer $\left(\mathrm{kg} . \text { farm }^{-1}\right)^{*}$ & -0.33 & $66.5( \pm 4.3)$ & $46.8( \pm 6.9)$ & $40.3( \pm 6.26)$ \\
\hline Animals (number.farm ${ }^{-1}$ )* & 0.37 & $16.5( \pm 1.0)$ & $20.3( \pm 1.4)$ & $25.2( \pm 1.1)$ \\
\hline Credit sources (number.farm ${ }^{-1}$ ) & -0.16 & $1.9( \pm 0.1)$ & $1.7( \pm 0.1)$ & $1.4( \pm 0.1)$ \\
\hline Slope $(\%)$ & -0.16 & $4.7( \pm 0.7)$ & $5.1( \pm 1.1)$ & $4.7( \pm 0.9)$ \\
\hline Elevation $(\mathrm{m})$ & 0.15 & $2009.1( \pm 6.3)$ & $2045.6( \pm 18.1)$ & $2140.2( \pm 26.2)$ \\
\hline Town distance $(\mathrm{km})^{*}$ & 0.45 & $5.1( \pm 0.3)$ & $7.1( \pm 0.8)$ & $10.6( \pm 0.8)$ \\
\hline Road distance $(\mathrm{km})^{*}$ & 0.36 & $3.1( \pm 0.3)$ & $4.6( \pm 0.6)$ & $6.3( \pm 0.5)$ \\
\hline
\end{tabular}

$* \mathrm{P}<0.05 ;$ Threshold $=0.2 / \sqrt{ }(1.5207)=0.162$

roads and towns (Fig. 6). The number of crop varieties decreased significantly (Table 4), the changes taking place mainly at farms located close to a road (Fig. 6c, d). Proximity of farms to a town was associated with low agro-biodiversity, both in 2000 and 2005 (Fig. 6a-d). Particularly, farms close to the towns of Adwa in the North-Western and Edga Arbi in the Eastern part of the study area showed a decrease in agrobiodiversity between 2000 and 2005 (Fig. 6c, d).

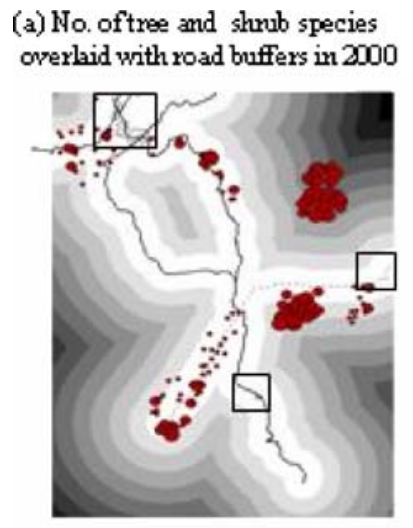

(c) No. of crop varieties overlaid with road buffers in 2000

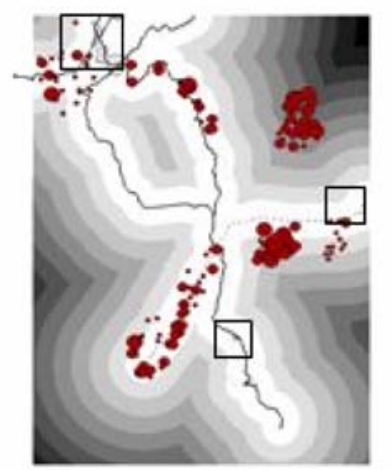

(b) No. of tree and shrub species orerlaid with road buffers in 2005

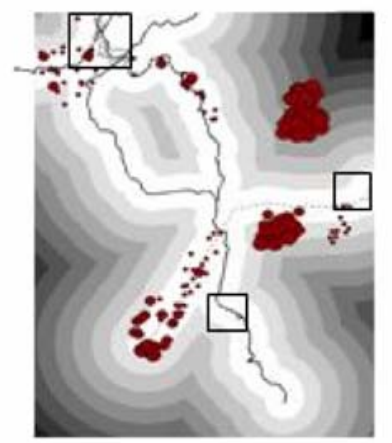

(d) No. of crop varieties overlaid with road buffers in 2005

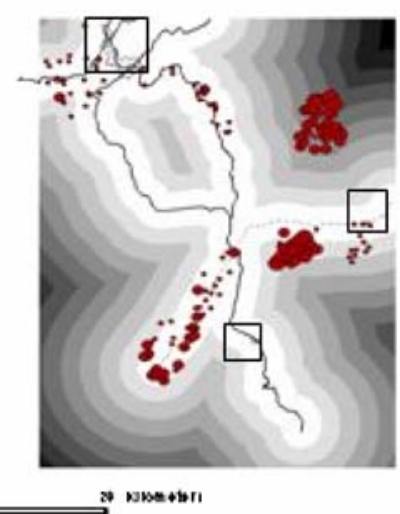

\section{No. treeishrub species} and crop variety per farm

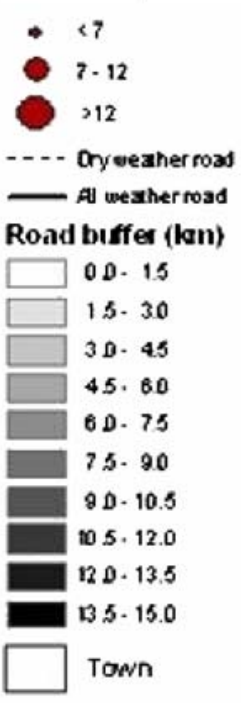

Fig. 6 Spatial distribution of tree and shrub species in 2000 (a) and 2005 (b) and number of crop varieties in 2000 (c) and 2005 (d) for the Tigray study area in Northern Ethiopia 


\section{Discussion}

Spatial and temporal variation in agro-biodiversity and soil degradation

This study integrated field measurements, farm surveys and GIS analysis of 151 farms to assess agro-biodiversity and soil degradation in relation to their proximate causes in a longitudinal study with observations in 2 years. The spatial and temporal analysis of our results demonstrate a decrease in agro-biodiversity, particularly in the number of crop varieties, on 84 farms, an increase on 36 farms and no change on 31 farms (Fig. 5 and Table 5). This decrease occurred mainly at farms where inorganic fertilizer use and the number of credit sources was relatively high (Table 5). Those farms with decreased numbers of crop landraces were mostly located close to towns and major roads (Fig. 6). Agro-biodiversity of the farm population as a whole did not decrease significantly (Table 4). This points to a major danger in averaging over space (as is done in a $t$-test) and emphasizes the importance of assessing agro-biodiversity at specific locations over time. No changes in soil erosion, the indicator of soil resource degradation, were detected. Although this analysis suffers from the fact that soil erosion was estimated by two different methods, viz. visual observations in 2000 and by calculation in 2005 , there was a significant correlation between the erosion scores obtained by these two methods in 2005 .

The study demonstrates that agro-biodiversity had decreased between 2000 and 2005 on farms close to the development drivers, towns and major roads, and on farms with better access to credit and with higher fertilizer use. Decreases in agro-biodiversity between 2000 and 2005 were associated with decreases in crop types, crop selection criteria and number of farm animals (Table 5). This indicates that intensification of agricultural practices with higher external inputs is detrimental to on-farm agrobiodiversity (including crop diversity as well as tree/shrub diversity), a process which is most prevalent close to towns and roads, at lower elevations. Brush et al. (1992) working with potato-based systems in the Andes also found that farms closer to towns and markets were more influenced by the introduction of modern crop varieties compared to those further away and showed decreased agro-biodiversity close to towns. The decrease in the number of crop varieties found in our study suggests that, in addition to the enhancement of external resource use, the development process is also one of specialization or simplification. Surprisingly, farms which exhibited this intensification pattern and associated low agro-biodiversity values were not positively but negatively associated with the production of food calories (data 2005; Table 2). This relationship held for all crops at the farms visited, except for maize, which had a larger total caloric content at intensively cultivated farms, partially because more maize was grown at these farms. The general negative association between agrobiodiversity and total caloric yield suggests that intensification does not appear to have the intended positive effect of increasing productivity, while exhibiting a range of undesirable side effects, including loss of crop diversity, onfarm trees, livestock, and soil $\mathrm{P}$ and $\mathrm{N}$ reserves. A similar conclusion was drawn by Mozumder and Berrens (2007) who showed that short term crop yield improvement strategies based on indiscriminate use of inorganic fertilizer enhances loss of agro-biodiversity.

Increases in agro-biodiversity were limited to a return to a larger number of crop varieties (landraces) at farms far from the nearest development drivers (town and road) and at higher elevation with higher numbers of planted crop types, numbers of crop selection criteria and animal manure application rates. These farms were predominantly located in region IV (Fig. 1) far from regional centers. There, farmers still practice traditional farming by growing diversified crop types selected by a range of criteria (e.g., yield, early maturity, drought resistance, market value, weed resistance, insect pest resistance, straw quality, threshability and beverage quality) (Hadgu et al., 2008a). Lack of access to markets forces these farmers to adopt subsistence strategies which rely on sustained maintenance of internal resources by highly diversified systems. Similar results were found in other studies: in Mexico (Van Dusen 2000), in Ethiopia (Benin et al. 2003) and at various locations in the Andes (Brush et al. 1992).

The plants in these diversified cropping systems were likely to have had resource utilization traits that were diverse, such as plant architecture, rooting depth, soil cover, and allocation of photosynthates (Russell 2002). These cropping systems included regularly spaced acacia trees, and resulted in higher caloric crop yields thanks to the nitrogen-fixing bacteria associated with acacia trees. The beneficial effects of acacia trees on barley yields were demonstrated in separate experiments (Hadgu et al. 2008c). Higher overall productivity per unit area can also be obtained when different species efficiently utilize nutrients, water and light because of their interspecific differences, resulting in complementarity and facilitation (Tilman et al. 1996; Picasso et al. 2008).

Further evidence of agricultural land use changes being the cause of agro-biodiversity decline is provided by the GIS analysis of land use types and agro-biodiversity in 2005 . Results (Fig. 3) demonstrate that the type of land that is sparsely cultivated is positively associated with high agrobiodiversity, while the type that is intensively cultivated is associated with medium and particularly with low agrobiodiversity. Earlier results (Hadgu et al. 2008c) showed that removal of the traditional tree species associated with intensification also removes significantly positive effects on yield of crops. Thus, a greater reliance on external nutrients 
first has to overcome this loss of ecosystem service, which may be one of the factors explaining lower caloric production in the more intensive systems in this study.

Similar to findings for 2000 (Hadgu et al. 2008a), soil erosion in 2005 was positively associated with slope and closeness to towns and roads (Table 3 and Fig. 4). These locations are dominated by the type of land that is intensively cultivated and where trees on farmland have been felled (Hadgu et al. 2008a). The significant increase of the number of pest species as stated by farmers on sites with higher erosion may be associated with this simplification of cropping systems but the data do not allow conclusions on this point. A negative association was observed between soil erosion, and soil $\mathrm{OM}$ and number of crop selection criteria. Pimentel and Kounang (1998) indicate that low soil OM facilitates water run off due to reduced water holding capacity of the soil. The consequence of high soil erosion frequently is low crop productivity as essential soil nutrients are lost in the process of erosion (Mokma and Sietz 1992). Whether soil deterioration associated with intensification indeed explains the low caloric productivity we found should be examined in more detail so that more appropriate intensification strategies may be devised.

\section{Comparison with other studies}

Unlike our study, which assessed spatial variation in both crop and non-crop diversity in relation to their proximate drivers, most other studies in Ethiopia describe (genetic) diversity in individual crops without considering external causes of changes in diversity. Those studies concerned varietal diversity in sorghum (Sorghum bicolor) (Mekbib 2008; Mulatu and Belete 2001; Teshome et al. 1999), wheat (Triticum spp.) (Di Falco et al. 2007; Kebebew et al. 2001), finger millet (Eleusine coracana) (Tsehaye et al. 2006), and tef (Eragrostis tef) (Assefa et al. 2001). A notable exception to these descriptive studies in Ethiopia is a study by Benin et al. (2003), which revealed determinants of cereal crop diversity. They found higher diversity on farms far from the nearest towns or markets, with higher livestock assets and higher education of family members. These results are in line with those of our study, which included a range of crops, except that we did not find a significant effect of education.

Higher on-farm agro-biodiversity in traditionally managed as compared to intensified agricultural production systems was also found in Ghana (Awanyo 2007), Nigeria (Netting and Stone 1996), Tanzania (Keller et al. 2006) and Peru (Pinedo-Vasquez et al. 2002). The last authors showed that traditional smallholder farming systems can manage agricultural activities while conserving agro-biodiversity. Netting and Stone (1996) and Keller et al. (2006) attributed the loss of agro-biodiversity to changes in land use resulting from socio-cultural and economic changes, such as expan- sion of urban areas and use of modern crop varieties. Agrobiodiversity decline on agricultural lands was also reported from the central Himalaya in India mainly because of changes in agricultural land use (Maikhuri et al. 2001), rapid socio-economic changes (replacement of mixed crops with uniform cash crops, changes in food habits, changes in social integration) and cultural changes (changes in traditional wisdom, faith and beliefs) (Nautiyal et al. 2008). Working in Sierra Norte de Puebla (SNP), a mountainous region of Mexico, Van Dusen and Taylor (2005) concluded that market integration, crop specialization and labor shortage contribute to the reduction in farm agro-biodiversity. However, Conelly and Chaiken (2000) argue that land use intensification and the use of modern crop varieties play a role in maintaining agro-biodiversity in agricultural lands in Hamisi, western Kenya. As farmers in Hamisi do not have large scale irrigable lands and are not led by market forces to focus on production of a single or narrow range of crops, agricultural intensification does not lead to specialization and reduction of agro-diversity (Conelly and Chaiken 2000).

\section{Implications}

This study provides for the first time information on status and dynamics of agro-biodiversity and soil degradation in one of the centers of diversity in Tigray, northern Ethiopia. Lack of information has thus far prevented policy analysts from taking such information into account. Increasing population pressure and associated food demands, and globalization (CSA 2004) may be expected to continue to drive changes in land use from traditional agricultural management to increased reliance on external resources. As indicated by our results, such changes are the main cause of loss of agro-biodiversity and do not have unequivocal positive effects on caloric production. Agricultural production by smallholder resourcepoor farmers cannot be sustainable if it depends on high input agricultural technologies because of the rising prices of inorganic fertilizer and uncertainties associated with environmental changes. The challenge is how to optimize agricultural productivity in a sustainable way while conserving agro-biodiversity in agricultural landscapes. Decision makers and land use planners should, therefore, consider agro-biodiversity as natural capital from which agriculture gains ecosystems services, such as soil fertility, protection against soil erosion, water retention and pest control (MEA 2005). As results of this research and previous studies show (Hadgu et al. 2008a, b, c), diversification of land use and farming strategies appear to be essential for future policies owing to their positive contribution to production. Policies that emphasize optimization of internal farm resources may well be better adapted to uncertain futures than policies which emphasize adoption of technology packages requiring high external inputs. 


\section{Conclusions}

This study revealed a significant loss of agro-biodiversity (numbers of trees/shrubs and crop land races) in agricultural landscapes between 2000 and 2005 in Tigray, northern Ethiopia. The loss of agro-biodiversity was higher on farms with higher inorganic fertilizer use and number of credit sources, which were mainly located close to towns and major roads. Agro-biodiversity was positively associated with number of crop types, crop selection criteria, and animals per farm. These farms were mainly located far from towns and major roads at high altitude locations. On-farm agro-biodiversity contributed to soil fertility and crop productivity. At a regional scale, intensively cultivated land (with few or no trees/shrubs) was associated with reduced agro-biodiversity. Reduced agro-biodiversity went hand-in-hand with higher soil erosion and lower soil organic matter content, signs of unsustainability. A better understanding of the relationships among agro-biodiversity, caloric productivity and sustainability (indicated by soil erosion) documented in this study can help to improve food security while maintaining agrobiodiversity resources in developing countries like Ethiopia.

Acknowledgments Financial support was provided by an IITALukas Brader Fellowship and a NUFFIC fellowship to the first author. We thank IITA for providing IITA-Lukas Brader Fellowship and $\mathrm{Mr}$ B. Oyewole, for logistic support, and Dr Morag Ferguson and Dr Michael Pillay, for being IITA supervisors. We also thank Dr Gerrit F. Epema for his assistance in the beginning of this research.

Open Access This article is distributed under the terms of the Creative Commons Attribution Noncommercial License which permits any noncommercial use, distribution, and reproduction in any medium, provided the original author(s) and source are credited.

\section{References}

Afifi AA, Clark V (1984) Computer-aided multivariate analysis. Van Nostrand Reinhold Company, New York

Assefa K, Tefera H, Merker A, Kefyalew T, Hundera F (2001) Quantitative trait diversity in tef [Eragrostis tef (Zucc.) Trotter] germplasm from Central and Northern Ethiopia. Genet Resour Crop Evol 48:53-61

Awanyo L (2007) A Janus-faced biodiversity change and the partiality of ecological knowledge in a world biodiversity hotspot in Ghana: implications for biodiversity rehabilitation. Geoforum 38:739-751

Benin S, Smale M, Gebremedhin B, Pender J, Ehui S (2003) The determinants of cereal crop diversity on farms in the Ethiopian highlands. EPTD discussion paper No. 105. International Food Policy Research Institute, Washington, D.C

Brush S, Taylor JE, Bellon MR (1992) Biological diversity and technology adoption in Andean potato agriculture. J Dev Econ 39:365-387

Borlaug NE (1996) Lost crops of Africa. National Academy Press, Washington DC

Chapin FS III, Zavaleta ES, Eviner VT, Naylor RL, Vitousek PM, Reynolds HL, Hooper DU, Lavorel S, Sala OE, Hobbie SE,
Mack MC, Díaz S (2000) Consequences of changing biodiversity. Nature 405:234-242

Conelly WT, Chaiken MS (2000) Intensive farming, agro-diversity, and food security under conditions of extreme population pressure in Western Kenya. Hum Ecol 28:19-51

CSA (2004) Statistical Abstracts. Ethiopian Central Statistical Authority (CSA), Addis Ababa

Di Falco S, Chavas J-P, Smale M (2007) Farmer management of production risk on degraded lands: the role of wheat variety diversity in the Tigray region, Ethiopia. Agric Econ 36:147-156

Drinkwater LE, Wagoner P, Sarrantonio M (1998) Legume-based cropping systems have reduced carbon and nitrogen losses. Nature 396:262-265

Deurloo HA, Haileselassie T (1994) Rehabilitation of degraded and degrading areas of Tigray, Ethiopia, survey on farm practices based on local knowledge. Wageningen Agricultural University, Wageningen

Edwards S, Tadesse M, Demissew S, Hedberg I (2000) Flora of Ethiopia and Eritrea. Addis Ababa University, Addis Ababa

FAO (2003) Food energy - methods of analysis and conversion factors. FAO, Rome

Feoli E, Vuerichm LG, Woldu Z (2002) Processes of environmental degradation and opportunities for rehabilitation in Adwa, Northern Ethiopia. Landsc Ecol 17:315-325

Hadgu KM, Epema GF, van Bruggen AHC (2008a) Biodiversity and Sustainability in Agricultural landscapes in Tigray, Northern Ethiopia. Landscape Urban Plan. (in press)

Hadgu KM, Kooistra L, Rossing WAH, van Bruggen AHC (2008b) Detection of land use/ land cover changes by remote sensing and associated drivers for the period 1964-2005 in the highlands of Tigray, Ethiopia. Agriculture, Ecosystems and Environment. (in press)

Hadgu KM, Kooistra L, Rossing WAH, van Bruggen AHC (2008c) Assessing the effect of Acacia albida based land use systems on barley yield at field and regional scale in the highlands of Tigray, Northern Ethiopia. Agroforestry Systems (submitted)

Hurni H (1985) Soil conservation manual for Ethiopia. A field guide for conservation implementation. Soil Conservation Research Project, Addis Ababa

Jackson LE, Pascual U, Hodgkin T (2007) Utilizing and conserving agrobiodiversity in agricultural landscapes. Agric Ecosyst Environ 121:196-210

Kebebew F, Tsehaye Y, McNeilly T (2001) Diversity of durum wheat (Triticum durum Desf.) at in situ conservation sites in North Shewa and Bale, Ethiopia. J Agric Sci 136:383-392

Keller GB, Mndiga H, Maass BL (2006) Diversity and genetic erosion of traditional vegetables in Tanzania from the farmer's point of view. Plant Genet Resour 3:400-413

Mekbib F (2008) Genetic erosion of sorghum (Sorghum bicolor (L.) Moench) in the centre of diversity, Ethiopia. Genet Resour Crop Evol 55:351-364

Maikhuri RK, Rao KS, Senwal RL (2001) Changing scenario of Himalayan agroecosystems: loss of agrobiodiversity, an indicator of environmental change in Central Himalaya, India. Environment 21:23-39

McNeely JA, Scherr SJ (2003) Ecoagriculture: strategies to feed the world and save wild biodiversity. Island Press, Washington, DC

Mokma DL, Sietz MA (1992) Effects of soil erosion on corn yields on Marlette soils in South-Central Michigan. J Soil Water Conserv 47:325-327

MEA (2005) Ecosystems and Human Well-being: Biodiversity Synthesis. In: Millennium Ecosystem Assessment (MEA). World Resources Institute, Washington, DC

MoNRDEP (1990) Soil analysis laboratory manual. Ministry of Natural Resources Development and Environmental Protection (MoNRDEP), Addis Ababa

Mooney HA, Cooper A, Reid W (2005) Confronting the human dilemma. Science 434:561-562 
Mozumder P, Berrens RP (2007) Inorganic fertilizer use and biodiversity risk: an empirical investigation. Ecol Econ 62:538-543

Mulatu E, Belete K (2001) Participatory varietal selection in lowland sorghum in eastern Ethiopia: impact on adoption and genetic diversity. Exp Agric 37:211-229

Nautiyal S, Bisht V, Rao KS, Maikhuri RK (2008) The role of cultural values in agrobiodiversity conservation: a case study from Uttarakhand, Himalaya. J Hum Ecol 23:1-6

Netting RM, Stone MP (1996) Agro-diversity on a farming frontier: Kofyar smallholders on the Benue plains of central Nigeria. J Int African Inst 66:52-70

Picasso VD, Brummer EC, Liebman M, Dixon PM, Wilsey BJ (2008) Crop species diversity affects productivity and weed suppression in perennial polycultures under two management strategies. Crop Sci 48:331-342

Pimentel D, Kounang N (1998) Ecology of soil erosion in ecosystems. Ecosystems 1:416-426

Pinedo-Vasquez M, Pasqualle JB, Del Castillo Torres D, Coffey K (2002) A tradition of change: the dynamic relationship between biodiversity and society in sector Muyuy, Peru. Environ Sci Policy 5:43-53

Qualset CO, McGuire PE, Warburton ML (1995) Agrobiodiversity key to agricultural productivity. Genetic resource conservation program. Calif Agric 49:45-49

Russell AE (2002) Relationships between crop-species diversity and soil characteristics in southwest Indian agroecosystems. Agric Ecosyst Environ 92:235-249

Sarraute JL, Vonder OW (1994) Rehabilitation of degraded and degrading areas of Tigray, Ethiopia: landsurface, landcover and change detection classifications based on remote sensing. Wageningen Agricultural University, Wageningen

SAS (1999) SAS/STAT User's manual, volume I. SAS Institute, Cary

Swift MJ, Izac AMN, van Noordwijk M (2004) Biodiversity and ecosystem services in agricultural landscapes - are we asking the right questions? Agric Ecosyst Environ 104:113-124

Teshome A, Fahrig L, Torrance JK, Lambert JD, Arnason ZJ, Baum BR (1999) Maintenance of Sorghum (Sorghum bicolor, Poaceae) landrace diversity by farmers' selection in Ethiopia. Econ Bot 53:79-88

Thrupp LA (2000) Linking agricultural biodiversity and food security: the valuable role of agrobiodiversity for sustainable agriculture. Int Aff 76:265-281

Tilman D, Wedin D, Knops J (1996) Productivity and sustainability influenced by biodiversity in grassland ecosystems. Nature 379:718-720

Tilman D, Reich P, Knops J, Wedin D, Mielke T, Lehman C (2001) Diversity and productivity in a long-term grassland experiment. Science 294:843-845

Tscharntke T, Klein AM, Steffan-Dewenter I, Thies C (2005) Landscape perspectives on agricultural intensification and biodiversity-ecosystem service management. Ecol Lett 8: 857-874

Tsehaye Y, Berg T, Tsegaye B, Tanto T (2006) Farmers' management of finger millet (Eleusine coracana L.) diversity in Tigray, Ethiopia and implications for on-farm conservation. Biodivers Conserv 15:4289-4308

Vandermeer J, Lawrence D, Symstad A, Hobbie S (2002) Effects of biodiversity on ecosystem functioning in managed ecosystems. In: Loreau M, Naeem S, Inchausti P (eds) Biodiversity and Ecosystem Functioning. Oxford University Press, Oxford, pp 157-168

Van Dusen E (2000) In situ conservation of crop genetic resources in the Mexican Milpa system. Doctoral dissertation. University of California-Davis, Davis

Van Dusen ME, Taylor JE (2005) Missing markets and crop diversity: evidence from Mexico. Environ Dev Econ 10:513-531
Wischmeier WH, Smith DD (1978) Predicting rainfall erosion losses: a guide to conservation planning. Agriculture Handbook 537. United States Department of Agriculture, Washington DC

WRI (2005) The wealth of the poor: managing ecosystems to fight poverty. World Resources Institute (WRI), Washington, DC

Wood D, Lenné JM (1999) Why agrobiodiversity? In: Wood D, Lenné JM (eds) Agrobiodiversity: characterization, utilization and management. CABI, Wallington, pp 1-13

Zhu YY, Chen H, Fan J, Wang Y, Li Y, Chen J, Fan J, Yang S, Hu L, Leung H, Mew TW, Teng PS, Wang Z, Mundt CC (2000) Genetic diversity and disease control in rice. Nature 406:718-722

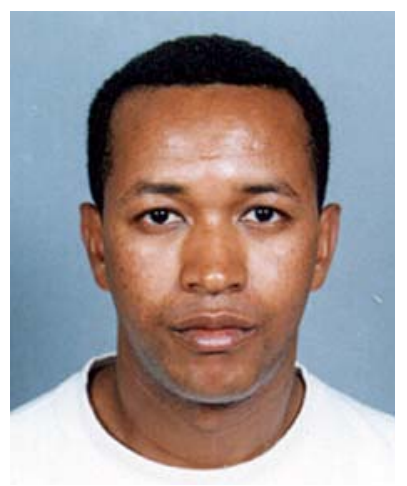

Kiros M. Hadgu obtained his BSc degree in Dryland Agriculture and Natural Resources from Mekelle University, Ethiopia. His MSc and $\mathrm{PhD}$, he received from Wageningen University in the Netherlands. Currently, he is working as lecturer at Mekelle University. His research interests are in the field of land use planning and watershed management using geo-information technology and remote sensing.

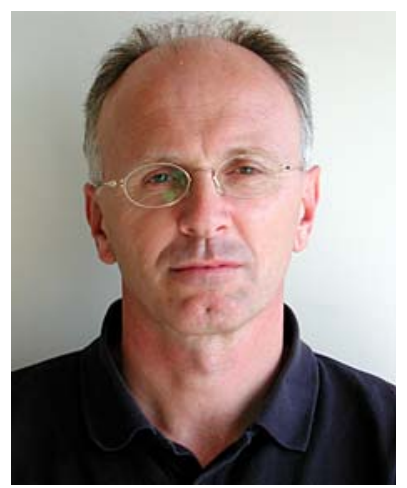

Walter A. H. Rossing obtained his $\mathrm{MSc}$ and $\mathrm{PhD}$ degrees in Theoretical Production Ecology from Wageningen University, the Netherlands. He currently is Associate Professor at Wageningen University. His research focuses on model-based design and analysis of organic and low-input farming systems, multifunctional agriculture and landscape design. 

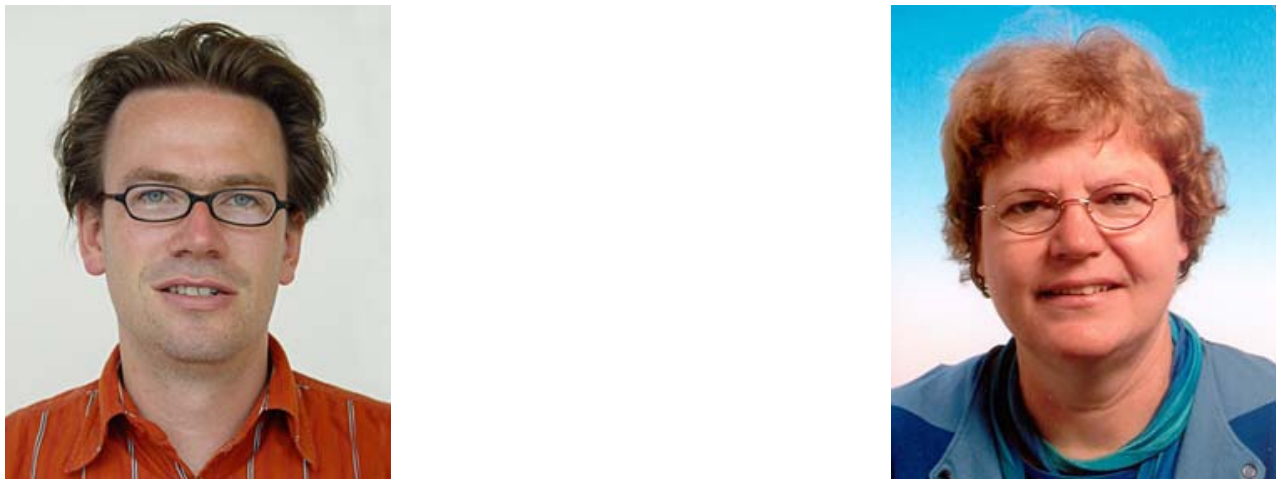

Lammert Kooistra obtained his MSc degree from Wageningen University and his $\mathrm{PhD}$ degree from the Radboud University in Nijmegen, the Netherlands. Currently, he is working as assistant professor at Wageningen University. His main research interest is the application of remote sensing for environmental conservation and management with special interest for imaging spectroscopy, sensor networks and ecological modelling.

Ariena H. C. van Bruggen obtained her MSc degree from Wageningen University and her PhD degree in Plant Pathology from Cornell University at Ithaca, New York, USA. She worked as Professor in Plant Pathology at UC Davis in California, USA, and is currently Professor of Biological Farming Systems at Wageningen University. Her research focuses on detection of ecological principles and patterns underlying the functioning of durable and organic farming systems, and soil and ecosystem health. 